\title{
Increased airway iron as a potential factor in the persistence of Pseudomonas aeruginosa infection in cystic fibrosis
}

\author{
D.W. Reid, V. Carroll, C. O'May, A. Champion and S.M. Kirov
}

ABSTRACT: Iron availability is critical to many bacteria and increased iron has been described in airway secretions in cystic fibrosis (CF). The main aim of the present study was to assess the relationship between iron in CF sputum and the quantitative bacterial burden.

Iron, ferritin and total cell counts (TCC) were assessed in sputum samples obtained from 15 clinically stable CF patients chronically infected with Pseudomonas aeruginosa. Sputum samples were also obtained at the commencement of episodes of acute exacerbation in 10 subjects and analyses were repeated in six of these exacerbation cases after i.v. antibiotic treatment. The relationship between iron indices and the presence of $\boldsymbol{P}$. aeruginosa, as well as total anaerobic bacterial load, was determined. Sputum was also obtained from 10 CF patients with no evidence of infection with $P$. aeruginosa and 11 normal healthy controls.

Sputum iron, ferritin and TCC were significantly elevated in all CF patients, even in those not infected with $P$. aeruginosa, compared with healthy controls. There was a strong positive relationship between sputum iron and $P$. aeruginosa in clinically stable patients, but not in samples obtained during an acute exacerbation. There was no relationship between sputum iron and anaerobic bacterial load. Antibiotic treatment significantly reduced sputum TCC and anaerobic bacterial load, but not iron, ferritin or the presence of $P$. aeruginosa during an exacerbation.

In conclusion, the present study suggests that increased airway iron may be important to Pseudomonas aeruginosa persistence in cystic fibrosis.

\section{KEYWORDS: Cystic fibrosis, iron, Pseudomonas aeruginosa}

ung homeostatic mechanisms normally keep extracellular iron levels as close to zero as possible [1]. There is good reason for this, since many pathogenic bacteria require iron for replication and respiration under both aerobic and anaerobic conditions. The increased availability of even small amounts of iron can profoundly increase bacterial virulence in the mammalian host, allowing bacterial replication to overwhelm the host's immune defence systems $[2,3]$. Additionally, free iron in an aerobic environment generates harmful oxidative hydroxyl radicals via the Haber-Weiss and Fenton reactions, which directly cause tissue damage [1].

Chronic infection of the airway with Pseudomonas aeruginosa characterises lung disease in cystic fibrosis (CF) [4]. The propensity for colonisation by $P$. aeruginosa at a very young age is the hallmark of this disease and isolation of mucoid, alginate-producing organisms from the respiratory tract is almost pathognomonic of CF [4].
However, despite many advances, it is still not understood why infection occurs in CF or how it relates to the basic genetic defect and cell membrane abnormalities of salt and water homeostasis $[4,5]$.

$P$. aeruginosa is able to exist in many different environments and in almost any ecological niche due, in part, to its efficient iron-sequestering mechanisms. Levels of iron in the lung environment are usually very low and relatively inaccessible, but recent data demonstrate unexpectedly high levels of extracellular iron in respiratory tract secretions from patients with CF [2, 3, 6-8]. The majority of excess iron in the CF lung is bound to the host's iron-binding protein ferritin. Previous findings by the present authors suggest that iron homeostasis in the CF lung under conditions of high iron load is probably coordinated in vivo by the pro-inflammatory cytokines interleukin-1G $\beta$ and tumour necrosis factor- $\alpha$ [9]. The question that remains is whether this

\section{AFFILIATIONS}

Cardiorespiratory Research Group, School of Medicine, University of Tasmania, Hobart, Australia.

CORRESPONDENCE

D.W. Reid

University of Tasmania Clinical School

43 Collins Street

Hobart 7000

Tasmania

Australia

Fax: 362264894

E-mail: d.e.c.reid@utas.edu.au

Received:

November 272006

Accepted after revision:

April 182007

SUPPORT STATEMENT

The present study was supported by a grant from the IRGS Scheme at the University of Tasmania (Hobart, Australia) and the National Health and Medical Research Council of Australia.

STATEMENT OF INTEREST None declared. 
increase in iron within the CF lung microenvironment has a role in facilitating bacterial replication, or whether it simply represents an inflammatory epiphenomenon. To shed light on this issue, the iron content in sputum samples from CF patients chronically infected with $P$. aeruginosa was determined during different phases of clinical disease. The relationship of iron content to quantitative bacterial load and sputum total cell counts (TCC) was also assessed, the latter as a measure of the intensity of the local host inflammatory response. A group of $10 \mathrm{CF}$ patients with no evidence of $P$. aeruginosa infection on repeated sputum culture results over a 2 -yr period and 11 normal healthy subjects with normal lung function (age median (range) 29 (21-58) yrs, forced expiratory volume in one second (FEV1) median (range) 95 (93-109)\% predicted) were also studied.

\section{METHODS}

\section{Subjects}

Individuals with CF were recruited from outpatient clinics or within $48 \mathrm{~h}$ of admission to hospital with an acute exacerbation of airway sepsis. Stable patients were required to have been exacerbation-free for a minimum period of 1 month. Most of these patients were on a maintenance cyclical regimen of oral or inhaled antibiotics. The individual regimens are detailed in tables 1 and 2 . In the acute patients, sputum samples were obtained as close to the commencement of an i.v. course of antibiotics as possible ( $<48 \mathrm{~h}$; individual regimens documented in table 3 ) in order to minimise the potential confounder of sudden changes in bacterial load with therapy, as this may have affected the relationship with sputum iron content. An acute exacerbation was defined as an increase in cough, sputum production and breathlessness. In a small number of the acute patients $(n=6)$, a repeat sputum sample was obtained $\geqslant 7$ days later (median (range) 8 (7-10) days), when patients demonstrated clinical improvement. Spontaneously expectorated sputum was obtained in all CF subjects. In two children in whom $P$. aeruginosa had not previously been isolated, it was not possible to obtain a sufficient sample with which to undertake quantitative bacterial load, but TCC and iron indices were determined, and a routine hospital clinical bacterial culture was performed.

In normal, non- $\mathrm{CF}$, healthy controls, sputum expectoration and processing were performed according to the method described by PIN et al. [10]. Sputum samples were transported on ice to the laboratory and processed within $4 \mathrm{~h}$. The Tasmanian statewide Human Research Ethics Committee (Australia) approved the study and all patients and controls gave informed written consent prior to providing a sputum sample.

\section{Sputum processing}

An aliquot of raw sputum free of salivary contamination was weighed and an equivalent volume to weight of dithiothreitol $(10 \%)$ was added. The sample was then gently vortexed and placed in a water bath at $38^{\circ} \mathrm{C}$ for $30 \mathrm{~min}$. At 10 -min intervals the sample was removed and gently vortexed once again. If the sample appeared particularly tenacious, further mixing was undertaken with gentle pipetting to ensure homogenisation. The sample was diluted a further five times with PBS, ensuring a constant final dilution of 10 times, and then centrifuged $(350 \times g$ for $15 \mathrm{~min})$. Following centrifugation, the cell-free

TABLE 1 Antibiotic regimens, clinical status, sputum inflammatory indices and quantitative bacterial load in stable cystic fibrosis patients chronically infected with Pseudomonas aeruginosa

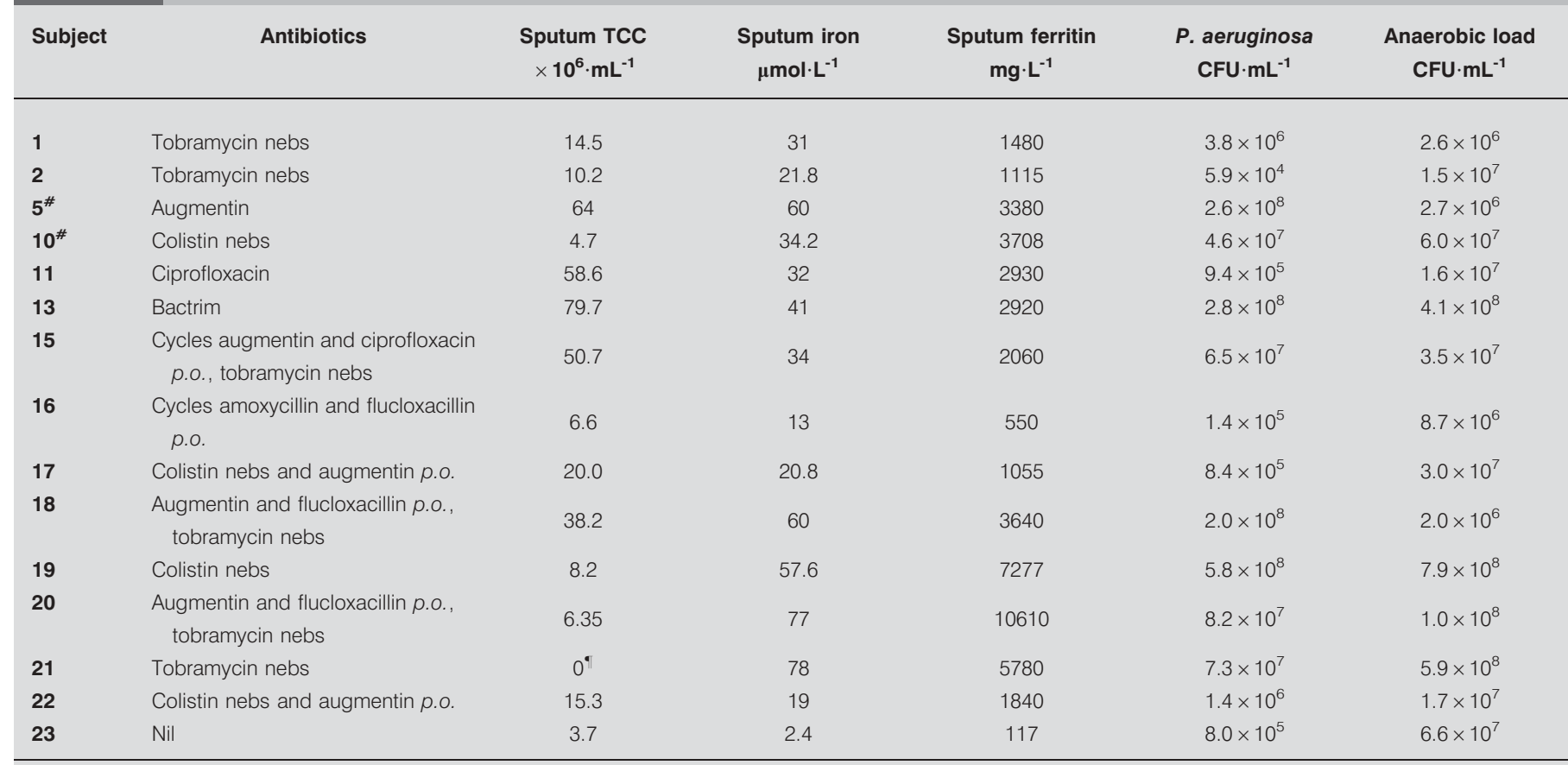

TCC: total cell counts; CFU: colony-forming units. ${ }^{*}$ : patients 5 and 10 provided sputum samples during both stable and acute phases (>1 month apart); ": a logistical error in the laboratory resulted in a sputum TCC not being performed. 


\begin{tabular}{|c|c|c|c|c|c|}
\hline TABLE & $\begin{array}{l}\text { Antibiotic regimens, clinical sta } \\
\text { Pseudomonas aeruginosa }\end{array}$ & indices and & terial load in & ystic fibrosis patients & not yet infected with \\
\hline Subject & Antibiotics & $\begin{array}{l}\text { Sputum TCC } \\
\times 10^{6} \cdot \mathrm{mL}^{-1}\end{array}$ & $\begin{array}{c}\text { Sputum iron } \\
\mu \mathrm{mol} \cdot \mathrm{L}^{-1}\end{array}$ & Sputum ferritin $\mathrm{mg} \cdot \mathrm{L}^{-1}$ & $\begin{array}{l}\text { Anaerobic bacterial load } \\
\text { CFU } \cdot \mathrm{mL}^{-1}\end{array}$ \\
\hline 1 & $\mathrm{Nil}$ & 40.1 & 20 & 2770 & $1.2 \times 10^{8}$ \\
\hline 2 & Augmentin p.o. & 11.0 & 16 & 1750 & N/A \\
\hline 5 & Cycles augmentin and flucloxacillin p.o. & 81.2 & 118 & 12720 & $2.64 \times 10^{9}$ \\
\hline 6 & Augmentin p.o. and tobramycin nebs & 6.9 & 41 & 1090 & $3.5 \times 10^{6}$ \\
\hline 7 & Ciprofloxacin p.o. and tobramycin nebs & 2.6 & 14 & 820 & N/A \\
\hline 8 & $\mathrm{Nil}$ & 26.3 & 10 & 3970 & $1.9 \times 10^{9}$ \\
\hline 9 & Nil & 6.0 & 8 & 410 & $1.6 \times 10^{7}$ \\
\hline
\end{tabular}

TCC: total cell counts; CFU: colony-forming units; nebs: nebulised; N/A: not available.

supernatant was decanted and stored at $-80^{\circ} \mathrm{C}$ in $1 \mathrm{~mL}$ aliquots for later analysis, and the cell pellet re-suspended in PBS for the TCC.

\section{Routine bacterial culture}

At the time of sputum processing, an aliquot of raw sputum was sent for routine bacterial culture by the Hospital Pathology laboratory (Rayal Hobart Hospital, Hobart, Australia). P. aeruginosa colonies were identified as being oxidase positive and with typical morphology, i.e. mucoid or nonmucoid, following culture on blood agar aerobically.

\section{Sputum analysis}

Sputum TCC were performed on $20 \mu \mathrm{L}$ of re-suspended cell pellet using a Neubauer haemocytometer (Neubauer, Wertheim, Germany). In addition to inflammatory cells, red blood cells (RBC) and buccal squamous cells were quantified to examine the potential contribution of occult haemorrhage to iron content and the degree of salivary contamination. Sputum samples with any evidence of blood contamination were excluded from further analysis.

\section{Bacterial isolation and quantitative bacterial load determination}

The total and $P$. aeruginosa bacterial loads were determined using an adaptation of the method described by WONG et al. [11]. Briefly, CF sputa homogenates were serially diluted in PBS-gelatin $(0.1 \%)$ and spread onto a variety of culture media, including Pseudomonas selective agar (PSA), an enteric selective agar (MacConkey or Cysteine lactose electrolyte deficient medium) and two horse blood agar (HBA) plates (one used for aerobic and the other for anaerobic incubation). PSA facilitates the isolation and quantification of $P$. aeruginosa, and characteristic colonies are identified according to their appearance (blue-green or brown-pigmented), having been incubated under aerobic conditions at $37^{\circ} \mathrm{C}$. Anaerobic incubation of HBA plates allowed the isolation and quantitation of most other relevant pathogens, such as Haemophilus influenzae, Staphylococcus aureus and Streptococcus pneumoniae $(P$. aeruginosa does not grow on HBA under anaerobic conditions without nitrogen supplementation). The selection of sputum plugs free of saliva ensured that contamination with bacteria from the oropharynx was minimised. Colony-forming units (CFU) were counted on all plates after incubation for $48 \mathrm{~h}$. Total anaerobic bacterial and $P$. aeruginosa loads were expressed as $\mathrm{CFU} \cdot \mathrm{mL}^{-1}$ of sputum.

\section{Iron and ferritin assays}

The total iron content of cell-free, sputum supernatant was determined using a colorimetric assay and expressed as $\mu \mathrm{mol} \cdot \mathrm{L}^{-1}$ (lower limit of detection $0.9 \mu \mathrm{mol} \cdot \mathrm{L}^{-1}$ ). This assay depends upon the conversion of ferric $\mathrm{Fe}^{3+}$ to ferrous $\mathrm{Fe}^{2+}$ iron using ascorbic acid, followed by the addition of 2,4,6-tri(2pyridyl)-5-triazine, which forms a blue complex with $\mathrm{Fe}^{2+}$. The intensity of the colour of the complex is proportional to the iron concentration and it is read at a wavelength of $590 \mathrm{~nm}$ on a Boehringer-Ingelheim/Hitachi 747 analyser (BoehringerIngelheim, Mannheim, Germany). The ferritin concentration was determined by microparticle enzyme immunoassay using an Abbott AXSYM analyser (Abbott, Minneapolis, Il, USA). This assay utilises antihuman ferritin antibody-coated latex particles and results are expressed as $\mathrm{mg} \cdot \mathrm{L}^{-1}$ (lower limit of detection $3 \mathrm{mg} \cdot \mathrm{L}^{-1}$ ).

\section{Statistics}

Data are expressed as median (range). Differences between subject groups were analysed using the Mann-Whitney U-test for non-normally distributed data. Correlations between inflammatory variables were analysed using the Spearman rank test. For the statistical analyses, a two-tailed $p \leqslant 0.05$ was considered to be statistically significant. Wilcoxon's signed rank test was used to compare sputum parameters before and after i.v. antibiotic treatment in acute patients followed from an admission.

\section{RESULTS}

As may be expected, CF patients not infected with $P$. aeruginosa were younger (age 15.5 (3-43) versus 23 (15-48) yrs; $\mathrm{p}<0.001$ ) and had a better FEV1 (76 (57-105) versus 54 (28-88)\% pred; $\mathrm{p}<0.001)$ compared with those individuals chronically infected with $P$. aeruginosa. There was no difference in nutritional status 
TABLE 3 Antibiotics regimens, clinical status, sputum indices and bacterial load in cystic fibrosis patients infected with Pseudomonas aeruginosa experiencing an acute exacerbation

\begin{tabular}{|c|c|c|c|c|c|c|}
\hline Subject & Current antibiotics & $\begin{array}{c}\text { Sputum TCC } \\
\times 10^{6} \cdot \mathrm{mL}^{-1}\end{array}$ & $\begin{array}{l}\text { Sputum iron } \\
\mu \mathrm{mol} \cdot \mathrm{L}^{-1}\end{array}$ & $\begin{array}{l}\text { Sputum ferritin } \\
\mathrm{mg} \cdot \mathrm{L}^{-1}\end{array}$ & $\begin{array}{l}\text { P. aeruginosa } \\
\text { CFU } \cdot \mathrm{mL}^{-1}\end{array}$ & $\begin{array}{c}\text { Anaerobic load } \\
\text { CFU } \cdot \mathrm{mL}^{-1}\end{array}$ \\
\hline $3^{\#}$ & Tobramycin nebs & 41.1 & 79 & 3270 & $4.3 \times 10^{7}$ & $9.1 \times 10^{6}$ \\
\hline $5^{\#}$ & Augmentin p.o. & 53.8 & 200 & 6200 & $1.12 \times 10^{8}$ & $1.08 \times 10^{8}$ \\
\hline $6^{\circ}$ & Meropenem and tobramycin i.v. & 267 & 26.4 & 2802 & $9.2 \times 10^{6}$ & $3.6 \times 10^{7}$ \\
\hline $9^{\#}$ & Nil & 73.0 & 49 & 4950 & $3.3 \times 10^{8}$ & $1.8 \times 10^{5}$ \\
\hline $10^{\#}$ & Colistin nebs & 18.03 & 69 & 4390 & $3.8 \times 10^{6}$ & $5.1 \times 10^{8}$ \\
\hline 12 & Meropenem and tobramycin i.v. & 28.0 & 44.1 & 4089 & $5.8 \times 10^{7}$ & $8.0 \times 10^{6}$ \\
\hline 14 & Ceftazidime and tobramycin i.v. & 40.3 & 13.5 & 6750 & $3.0 \times 10^{8}$ & $1.2 \times 10^{8}$ \\
\hline
\end{tabular}

TCC: total cell counts; CFU: colony-forming units; nebs: nebulised. ${ }^{*}$ : sputum samples were obtained prior to commencement of $i . v$. antibiotics; ": patient very unwell on admission with predominantly viral symptoms. The patient was also treated with oral roxithromycin and bactrim (sulphomethoxazole/trimethoprim).

between the two CF groups as measured by the body mass index (data not shown).

The individual clinical characteristics, microbial flora, quantitative bacterial indices and sputum iron content of the $\mathrm{CF}$ patients are supplied in tables 1-5. All sputum indices in CF patients chronically infected with $P$. aeruginosa, whatever their clinical status, were grossly elevated compared with normal controls $(p<0.001)$. Sputum TCC, iron and ferritin levels tended to be higher in $\mathrm{CF}$ patients experiencing an acute exacerbation compared with stable patients. However, $P$. aeruginosa colony numbers were very similar in acute and stable CF patients (table 6). Interestingly, the anaerobic bacterial load was also very high and similar between the $\mathrm{CF}$

TABLE 4 Demographics of adult cystic fibrosis patients (stable and acute) infected with Pseudomonas aeruginosa

\begin{tabular}{|c|c|c|c|c|c|}
\hline Subject & Age yrs & Sex & $\mathrm{BMI} \mathbf{k g} \cdot \mathrm{m}^{-2}$ & FEV $1 \%$ & Microbiology \\
\hline 1 & 32 & $\mathrm{~F}$ & 21 & 23 & P. aeruginosa (muc), S. aureus \\
\hline 2 & 22 & $\mathrm{~F}$ & 26 & 30 & P. aeruginosa (muc, nonmuc), A. fumigatus \\
\hline 4 & 18 & $\mathrm{~F}$ & 18 & 30 & P. aeruginosa (muc, nonmuc) \\
\hline 5 & 20 & M & 17 & 59 & P. aeruginosa (muc, nonmuc), S. maltophilia \\
\hline 8 & 23 & $\mathrm{~F}$ & 20 & 68 & P. aeruginosa (muc, nonmuc) \\
\hline 9 & 21 & $\mathrm{~F}$ & 20 & 88 & P. aeruginosa (muc, nonmuc), S. aureus \\
\hline 10 & 20 & M & 21 & 67 & P. aeruginosa (muc, nonmuc) \\
\hline 11 & 23 & M & 21 & 69 & P. aeruginosa (muc, nonmuc), S. aureus \\
\hline 12 & 48 & M & 20 & 54 & P. aeruginosa (muc, nonmuc), A. fumigatus \\
\hline 13 & 17 & M & 20 & 50 & P. aeruginosa (muc) \\
\hline 18 & 25 & M & 19 & 27 & P. aeruginosa (muc, nonmuc), A. fumigatus \\
\hline 19 & 19 & $\mathrm{~F}$ & 25 & 54 & P. aeruginosa (muc, nonmuc), S. maltophilia \\
\hline 20 & 16 & $\mathrm{~F}$ & 19 & 68 & P. aeruginosa (muc, nonmuc), S. aureus, A. fumigatus \\
\hline 21 & 25 & M & 19 & 74 & P. aeruginosa (muc, nonmuc), S. aureus \\
\hline 22 & 45 & M & 21 & 60 & P. aeruginosa (muc, nonmuc) \\
\hline 23 & 15 & $\mathrm{~F}$ & 19 & 66 & $P$. aeruginosa (muc, nonmuc), $S$. aureus, $H$. influenzae, A. fumigatus \\
\hline
\end{tabular}

BMI: body mass index; FEV1: forced expiratory volume in one second; F: female; muc: mucoid colonies; S. aureus: Staphylococcus aureus; nonmuc: nonmucoid colonies; A. fumigatus: Aspergillus fumigatus; N/A: not available; M: male; S. maltophilia: Stenotrophomonas maltophilia; H. influenzae: Haemophilus influenzae. 
TABLE 5 Demographics of cystic fibrosis patients not yet infected with Pseudomonas aeruginosa

\begin{tabular}{|c|c|c|c|c|c|}
\hline Subject & Age yrs & Sex & BMI $\mathbf{k g} \cdot \mathrm{m}^{-2}$ & FEV $_{1} \%$ & Microbiology \\
\hline 1 & 18 & M & 20 & 92 & S. aureus \\
\hline 3 & 16 & $\mathrm{~F}$ & 18 & 105 & S. aureus \\
\hline 4 & 15 & M & 15 & 74 & S. aureus, A. fumigatus \\
\hline 5 & 43 & M & 27 & 57 & S. aureus \\
\hline 8 & 4 & M & N/A & N/A & S. aureus, S. maltophilia, A. fumigatus \\
\hline 9 & 17 & M & 18 & 75 & S. Aureus, A. fumigatus \\
\hline 10 & 12 & M & 15 & 65 & S. aureus, S. maltophilia, A. xylosidans \\
\hline
\end{tabular}

BMI: body mass index; FEV1: forced expiratory volume in one second; M: male; S. aureus: Staphylococcus aureus; F: female; A. fumigatus: Aspergillus fumigatus; N/A: not available; S. maltophilia: Stenotrophomonas maltophilia; Alc. xylosidans: Alcalagines xylosidans.

patient groups, equalling or even exceeding $P$. aeruginosa numbers in those CF patients chronically infected with this organism (table 6).

Sputum TCC, iron and ferritin levels in CF patients not infected with $P$. aeruginosa were also significantly increased compared with normal controls $(\mathrm{p}<0.001)$. Sputum indices in patients not infected with $P$. aeruginosa were very similar to those in patients chronically infected with $P$. aeruginosa except for sputum iron levels, which were significantly higher in the latter group ( $\mathrm{p}=0.01$; table 6$)$.

In the sputum samples examined, $\mathrm{RBC}$ contributed $<1 \%$ of the total cell numbers, i.e. $<2 \times 10^{5} \mathrm{RBC} \cdot \mathrm{mL}^{-1}$. This would account for an average sputum iron content of only $0.4 \mu \mathrm{mol} \cdot \mathrm{L}^{-1}$ compared with the high sputum iron levels (43 (2.4200) $\mu \mathrm{mol} \cdot \mathrm{L}^{-1}$ ) that were detected in the CF patients overall.

A number of significant correlations were apparent between bacterial load and iron-related indices in the CF patients. Sputum iron and ferritin concentrations were positively and strongly related to CFU of $P$. aeruginosa in samples obtained from stable patients $\left(\mathrm{r}^{2}=0.67, \mathrm{p}<0.001\right.$ and $\mathrm{r}^{2}=0.60, \mathrm{p}=0.001$, respectively; fig. 1); however, sputum iron was not related to anaerobic load in these individuals. In acute patients, there was no relationship between sputum iron or TCC and bacterial numbers, but there was a positive relationship between sputum ferritin and CFU of $P$. aeruginosa $\left(\mathrm{r}^{2}=0.50, \mathrm{p}=0.02\right)$. Sputum TCC in both stable and acute patients were not related to iron indices suggesting that airway inflammation, at least on this index of the host response, is not specifically related to the presence of iron. Consistently with previously published observations by the present authors, sputum iron and ferritin concentrations were positively related in all the CF sputum samples $\left(\mathrm{r}^{2}=0.53, \mathrm{p}<0.001\right)$, but particularly in stable individuals $\left(r^{2}=0.82, p<0.001\right)$ [9].

In CF patients not yet infected with $P$. aeruginosa, the total anaerobic bacterial load was significantly related to sputum TCC and ferritin $\left(\mathrm{r}^{2}=0.73, \mathrm{p}<0.01\right.$ and $\mathrm{r}^{2}=0.86, \mathrm{p}=0.001$, respectively), but not iron concentrations $\left(\mathrm{r}^{2}=0.04, \mathrm{p}=0.7\right)$.

Following i.v. antibiotic treatment for an acute exacerbation, despite clinical improvement and a significant reduction in sputum TCC as a measure of airway inflammation $(p=0.03)$, there was little overall change in iron indices or quantitative

TABLE 6 Sputum and bacterial load results in cystic fibrosis patients depending on clinical status

\begin{tabular}{|c|c|c|c|c|c|c|}
\hline Clinical status & Subjects $n$ & $\begin{array}{c}\text { Sputum TCC } \\
\times 10^{6} \cdot \mathrm{mL}^{-1}\end{array}$ & $\begin{array}{c}\text { Sputum iron } \\
\mu \mathrm{mol} \cdot \mathrm{L}^{-1}\end{array}$ & $\begin{array}{l}\text { Sputum ferritin } \\
\mathrm{mg} \cdot \mathrm{L}^{-1}\end{array}$ & P. aeruginosa $\mathrm{CFU} \cdot \mathrm{mL}^{-1}$ & Total anaerobic load CFU $\mathrm{mL}^{-1}$ \\
\hline
\end{tabular}

\begin{tabular}{|c|c|c|c|c|c|c|}
\hline \multicolumn{7}{|l|}{ P. aeruginosa } \\
\hline Stable, infected & 15 & $14.9(3.7-79.7)$ & $34.0(2.4-78.0)$ & 2920 (117-10610) & $4.6 \times 10^{7}\left(5.9 \times 10^{4}-5.8 \times 10^{8}\right)$ & $3.0 \times 10^{7}\left(2.0 \times 10^{6}-7.9 \times 10^{8}\right)$ \\
\hline $\begin{array}{l}\text { Stable, not } \\
\text { infected }\end{array}$ & 10 & $14.9(2.6-81.2)$ & $18.0(8-118)$ & $1706(410-12720)$ & 0 & $7.95 \times 10^{7}\left(3.5 \times 10^{6}-2.6 \times 10^{9}\right)^{5}$ \\
\hline Normal controls & 11 & $0.9(0.1-2.9)$ & $0(0-15.8)$ & $221(4-326)$ & ND & ND \\
\hline
\end{tabular}




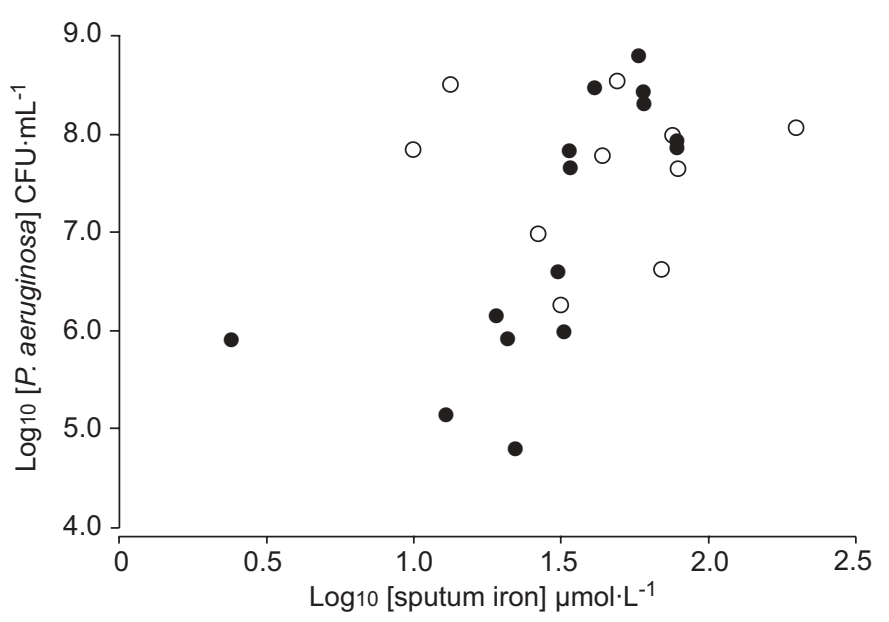

FIGURE 1. Relationship between sputum iron content and Pseudomonas aeruginosa colony-forming units $(\mathrm{CFU}) \cdot \mathrm{mL}^{-1}$ in cystic fibrosis patients. Logtransformed data are used for clarity of presentation. $\bullet$ : stable patient samples $\left(r^{2}=0.67, p<0.001\right)$; $O$ : patients with exacerbations $\left(r^{2}=0.004, p=0.9\right)$.

load of $P$. aeruginosa (table 7). However, there was a significant and almost $\log$ reduction in total anaerobic load $(\mathrm{p}=0.046)$.

\section{DISCUSSION}

The present study demonstrates a significant relationship between the iron content of the $\mathrm{CF}$ lung microenvironment and the quantitative load of $P$. aeruginosa. Patients with CF who had no detectable $P$. aeruginosa presence also had elevated sputum iron and ferritin levels compared with normal controls, suggesting increased iron may be an early event that pre-dates $P$. aeruginosa infection. Conventional i.v. antibiotic treatment for acute exacerbation in a small number of patients did not affect iron indices or substantially reduce $P$. aeruginosa numbers, but did significantly reduce sputum cell counts as a marker of inflammation, as well as total anaerobic bacterial load.

Airway secretions are normally iron depleted and much effort has been directed toward elucidating the strategies employed by $P$. aeruginosa to allow it to survive in a supposedly nutrient poor, particularly with regard to iron, environment [1]. There are some suggestions based on in vitro work using laboratory strains that this absence of iron may be one of the factors that drives this normally aerobic bacterium to adopt an anaerobic and biofilm mode of growth within the CF lung [12]. The present findings relating to increased iron content in the CF lung, even in patients not infected with $P$. aeruginosa, refute this explanation. The argument is inherently counter-intuitive, because $P$. aeruginosa requires iron under anaerobic conditions to generate energy through the process of de-nitrification, and iron is also important to the structural integrity of biofilms [13-17].

The finding of an increase in sputum iron content and a positive relationship to $P$. aeruginosa quantitative load in the present study, particularly in stable CF patients, offers a biologically plausible explanation, at least for $P$. aeruginosa survival and growth in this disease. Although the present study was predominantly cross-sectional, a small number of patients were followed through an exacerbation episode and it was found that antibiotic treatment failed to reduce ironrelated indices or CFU of $P$. aeruginosa. However, despite this, patients improved clinically and airway inflammation was reduced. The failure of specific, targeted antibiotic therapy to significantly reduce $P$. aeruginosa is interesting, but consistent with the hypothesis that the iron-enriched environment of the CF lung favours $P$. aeruginosa replication. There are plentiful in vitro and animal study data to suggest that iron is critical to bacterial replication, as well as to the steps required for biofilm development, i.e. aggregation and loss of motility [18, 19]. Adequate iron levels will remove a barrier to replication and help P. aeruginosa combat and overcome local host defences [3]. An increase in iron will also directly impair neutrophil function and rapidly saturate the binding capacities of lactoferrin and transferrin, negating their antimicrobial effects [20-22]. Destruction of lactoferrin within the airways by proteolysis will further impair the capacity of the innate immune system to prevent the establishment of bacterial biofilms in the CF lung [23, 24]. All these observations suggest that the presence of increased extracellular iron in the lung will adversely affect the CF host's ability to eradicate or control $P$. aeruginosa infection.

The presence of increased iron in sputum samples from patients not infected with $P$. aeruginosa suggests that the CF lung environment is primed for infection by this bacterium. This may be one of the factors responsible for the early age at which $P$. aeruginosa infects the CF lung, although other abnormalities of the CF lung environment and the local innate immune system related to cell membrane abnormality will undoubtedly contribute [24-26]. The very strong correlation between sputum iron and ferritin suggests that most of the iron is associated with this protein, but ferritin readily releases its iron core in the presence of proteases, $\mathrm{H}_{2} \mathrm{O}_{2}$ and free radicals produced by activated neutrophils [1]. P. aeruginosa siderophores and extracellular enzymes also liberate iron from ferritin with relative ease, and the milieu found within anaerobic biofilms, such as a low redox potential and acidic $\mathrm{pH}$, will facilitate iron acquisition [27]. These environmental conditions are well

TABLE 7 Sputum iron-related indices and bacterial loads before and after i.v. antibiotic treatment for an acute exacerbation

\begin{tabular}{|c|c|c|c|c|c|c|}
\hline Subjects $n$ & & $\begin{array}{c}\text { Sputum TCC } \\
\times 10^{6} \cdot \mathrm{mL}^{-1}\end{array}$ & $\begin{array}{l}\text { Sputum iron } \\
\mu \mathrm{mol} \cdot \mathrm{L}^{-1}\end{array}$ & $\begin{array}{l}\text { Sputum ferritin } \\
\mathrm{mg} \cdot \mathrm{L}^{-1}\end{array}$ & P. aeruginosa $\mathrm{CFU} \cdot \mathrm{mL}^{-1}$ & $\begin{array}{l}\text { Total anaerobic load } \\
\text { CFU } \cdot \mathrm{mL}^{-1}\end{array}$ \\
\hline Acute & 6 & $35.1(17.4-267)$ & $35.3(10-200)$ & $4245(1410-6750)$ & $7.7 \times 10^{7}\left(9.2 \times 10^{6}-3.0 \times 10^{8}\right)$ & $4.8 \times 10^{7}\left(8.0 \times 10^{6}-1.2 \times 10^{8}\right)$ \\
\hline
\end{tabular}

TCC: total cell counts; $P$. aeruginosa: Pseudomonas aeruginosa; CFU: colony-forming units. ${ }^{\#}: p=0.03 ;{ }^{\bullet}: p=0.046$ (both compared with baseline) 
described in the CF lung and favour the formation of usable $\mathrm{Fe}^{2+}$ from the relatively insoluble $\mathrm{Fe}^{3+}[28,29]$.

In summary, the present findings suggest that increased iron in the cystic fibrosis airway may play an important role in facilitating Pseudomonas aeruginosa infection and may possibly contribute to anaerobic biofilm growth. Recognition of the importance of available iron in determining the outcome of infection in cystic fibrosis may allow the development of more targeted therapies designed to interfere with iron accessibility. Consideration should be given to commencing these interventions at as early an age as is practicable. The early age at which Pseudomonas aeruginosa infects the cystic fibrosis lung and the obvious success of this organism have not been adequately explained according to the current understanding of cell membrane abnormalities, although several explanations have been proposed [24-26].

\section{ACKNOWLEDGEMENTS}

The present authors would like to thank I. Lamont (University of Otago, Dunedin, New Zealand) for proofreading the manuscript and for his helpful comments.

\section{REFERENCES}

1 Mateos F, Brock JH, Perez-Arellano JL. Iron metabolism in the lower respiratory tract. Thorax 1998; 53: 594-600.

2 van Asbeck BS, Verhoef J. Iron and host defence. Eur J Clin Microbiol 1983; 2: 6-10.

3 Ward CG, Bullen JJ, Rogers HJ. Iron and infection: new developments and their implications. J Trauma 1996; 41: 356-364.

4 Hoiby N. Cystic fibrosis: infection. Schweiz Med Wochenschr 1991; 121: 105-109.

5 Collins FS, Riordan JR, Tsui LC. The cystic fibrosis gene: isolation and significance. Hosp Pract (Off Ed) 1990; 25: 47-57.

6 Stites SW, Plautz MW, Bailey K, O'Brien-Ladner AR, Wesselius LJ. Increased concentrations of iron and isoferritins in the lower respiratory tract of patients with stable cystic fibrosis. Am J Respir Crit Care Med 1999; 160: 796-801.

7 Stites SW, Walters B, O'Brien-Ladner AR, Bailey K, Wesselius LJ. Increased iron and ferritin content of sputum from patients with cystic fibrosis or chronic bronchitis. Chest 1998; 114: 814-819.

8 Reid DW, Withers NJ, Francis L, Wilson JW, Kotsimbos TC. Iron deficiency in cystic fibrosis: relationship to lung disease severity and chronic Pseudomonas aeruginosa infection. Chest 2002; 121: 48-54.

9 Reid DW, Lam QT, Schneider H, Walters EH. Airway iron and iron-regulatory cytokines in cystic fibrosis. Eur Respir J 2004; 24: 286-291.

10 Pin I, Gibson PG, Kolendowicz R, et al. Use of induced sputum cell counts to investigate airway inflammation in asthma. Thorax 1992; 47: 25-29.

11 Wong K, Roberts MC, Owens L, Fife M, Smith AL. Selective media for the quantitation of bacteria in cystic fibrosis sputum. J Med Microbiol 1984; 17: 113-119.

12 Kim EJ, Sabra W, Zeng AP. Iron deficiency leads to inhibition of oxygen transfer and enhanced formation of virulence factors in cultures of Pseudomonas aeruginosa PAO1. Microbiology 2003; 149: 2627-2634.
13 Wasser IM, de Vries S, Moenne-Loccoz P, Schroder I, Karlin KD. Nitric oxide in biological denitrification: $\mathrm{Fe} / \mathrm{Cu}$ metalloenzyme and metal complex $\mathrm{NO}(\mathrm{x})$ redox chemistry. Chem Rev 2002; 102: 1201-1234.

14 Hassett DJ, Cuppoletti J, Trapnell B, et al. Anaerobic metabolism and quorum sensing by Pseudomonas aeruginosa biofilms in chronically infected cystic fibrosis airways: rethinking antibiotic treatment strategies and drug targets. Adv Drug Deliv Rev 2002; 54: 1425-1443.

15 Morrissey BM, Schilling K, Weil JV, Silkoff PE, Rodman DM. Nitric oxide and protein nitration in the cystic fibrosis airway. Arch Biochem Biophys 2002; 406: 33-39.

16 Chen X, Stewart PS. Role of electrostatic interactions in cohesion of bacterial biofilms. Appl Microbiol Biotechnol 2002; 59: 718-720.

17 Goldberg JB, Pier GB. The role of the CFTR in susceptibility to Pseudomonas aeruginosa infections in cystic fibrosis. Trends Microbiol 2000; 8: 514-520.

18 Berlutti F, Morea C, Battistoni A, et al. Iron availability influences aggregation, biofilm, adhesion and invasion of Pseudomonas aeruginosa and Burkholderia cenocepacia. Int J Immunopathol Pharmacol 2005; 18: 661-670.

19 Banin E, Vasil ML, Greenberg EP. Iron and Pseudomonas aeruginosa biofilm formation. Proc Natl Acad Sci USA 2005; 102: 11076-11081.

20 Sunder-Plassmann G, Patruta SI, Horl WH. Pathobiology of the role of iron in infection. Am J Kidney Dis 1999; 34: Suppl. 2, S25-S29.

21 Vallyathan V, Mega JF, Shi X, Dalal NS. Enhanced generation of free radicals from phagocytes induced by mineral dusts. Am J Respir Cell Mol Biol 1992; 6: 404-413.

22 Hoepelman IM, Jaarsma EY, Verhoef J, Marx JJ. Polynuclear iron complexes impair the function of polymorphonuclear granulocytes. Br J Haematol 1988; 68: 385-389.

23 Britigan BE, Hayek MB, Doebbeling BN, Fick RB Jr. Transferrin and lactoferrin undergo proteolytic cleavage in the Pseudomonas aeruginosa-infected lungs of patients with cystic fibrosis. Infect Immun 1993; 61: 5049-5055.

24 Rogan MP, Taggart CC, Greene CM, Murphy PG, O'Neill SJ, McElvaney NG. Loss of microbicidal activity and increased formation of biofilm due to decreased lactoferrin activity in patients with cystic fibrosis. I Infect Dis 2004; 190: 1245-1253.

25 Goldman MJ, Anderson GM, Stolzenberg ED, Kari UP, Zasloff M, Wilson JM. Human beta-defensin-1 is a saltsensitive antibiotic in lung that is inactivated in cystic fibrosis. Cell 1997; 88: 553-560.

26 Kelley TJ, Drumm ML. Inducible nitric oxide synthase expression is reduced in cystic fibrosis murine and human airway epithelial cells. J Clin Invest 1998; 102: 1200-1207.

27 Vasil ML, Ochsner UA. The response of Pseudomonas aeruginosa to iron: genetics, biochemistry and virulence. Mol Microbiol 1999; 34: 399-413.

28 Worlitzsch D, Tarran R, Ulrich M, et al. Effects of reduced mucus oxygen concentration in airway Pseudomonas infections of cystic fibrosis patients. J Clin Invest 2002; 109: 317-325.

29 Tate S, MacGregor G, Davis M, Innes JA, Greening AP. Airways in cystic fibrosis are acidified: detection by exhaled breath condensate. Thorax 2002; 57: 926-929. 